DOI: https//doi.org/10.13037/ci.vol22n50.8089

\title{
Os espaços de uso dla teoria: uma cartografia inicial das revistas científicas de Comunicação ${ }^{1}$
}

\author{
Los espacios de los usos de la teoría: una cartografía inicial de las revistas \\ científicas en Comunicación
}

Places for theory uses: an initial cartography of scientific journals in Communication

\author{
Luis Mauro Sá Martino ai \\ ORCID: http://orcid.org/0000-0002-5099-1741
}

Recebido em: 09/09/2021. Aprovado em: 27/10/2021

\section{Resumo}

Este artigo delineia algumas condições de circulação da produção científica em Comunicação nos periódicos da Área. A partir do estudo das temáticas, distribuição geográfica e cronológica e normas de 52 revistas de PPG ou associações de pesquisa foram observados três pontos: (1) as publicações se apresentam como espaço de formação do capital científico; (2) $82 \%$ discutem interfaces da comunicação com outras áreas, em ampla diversidade de assuntos; (3) apenas 17\% abrem espaço para a publicação por outras titulações além de doutores. Discutem-se esses resultados a partir de uma perspectiva epistemológica.

Palavras-chave: Teoria da Comunicação. Revistas Acadêmicas. Epistemologia.

\section{Abstract}

This paper outlines some conditions for the circulation of scientific knowledge in Communication grounded on the area's main journals. It studies the themes, geographical and chronological distribution and publication rules of 52 magazines. Analysis has shown three main characteristics: (1) publications responsible for the formation of the Area's scientific capital; (2) $82 \%$ of publications discuss communication interfaces with other areas, in a wide range of subjects; (3) the publication of doctors (or in co-authorship with doctors) is the majority: only $17 \%$ of the journals make room for individual publications of other titles.

Keywords: Communication Theory. Academic Journals. Epistemology.

\section{Introdução}

Todos os anos, cinquenta e duas revistas acadêmicas de Comunicação são publicadas no Brasil, vinculadas a programas de pós-graduação ou associações de pesquisa. Levando em conta uma periodicidade no mínimo semestral, há cento e quatro números anuais. Se cada um trouxer de oito a dez textos, pode-se estimar algo em torno

\footnotetext{
${ }^{1}$ Uma versão inicial deste trabalho foi apresentada ao NP Teorias da Comunicação do $43^{\circ}$ Congresso da Intercom. $\mathrm{O}$ autor agradece as críticas e sugestões recebidas na ocasião. Este trabalho é parte de um projeto de pesquisa desenvolvido com auxílio do CNPq - Processo 311528/2019-8.

${ }^{a}$ Faculdade Cásper Líbero. São Paulo/Brasil. E-mail: 1msamartino@gmail.com
} 
de mil artigos científicos publicados no país - e o número tende a ser maior, levandose em conta as revistas quadrimestrais ou com maior quantidade de textos por edição.

Esses números podem levantar, de saída, algumas questões.

Talvez a primeira seja quem conseguiria acompanhar esse montante de textos. Como ressaltam França e Prado (2013, p. 80), "pelo menos no Brasil, a quantidade de publicações que se disponibiliza anualmente ultrapassa em muito nossa capacidade de leitura e discussão. Preocupados em escrever, não damos conta de ler o que se publica". Um dos resultados é o baixo índice de impacto das publicações, indicam os autores, expresso na falta de citações dos artigos publicados.

Um segundo aspecto diz respeito à vitalidade da Área: trata-se de uma produção considerável, sobretudo imaginando que, diante do sistema de avaliação, para cada texto publicado corresponda um número maior - seria impossível saber exatamente de artigos submetidos, mas não aceitos. Essa produção, que não chega às páginas das revistas, é também indicativa da atividade desenvolvida por pesquisadoras e pesquisadores da Comunicação - sem mencionar a quantidade de pareceres elaborados. Seria possível, ao mesmo tempo, questionar em que medida não se trata de uma decorrência do "produtivismo" (FRANÇA; PRADO, 2013).

Consolidada, a Área não apenas tem o que dizer, mas também se apresenta em plena atividade no estabelecimento de diálogos entre as diversas perspectivas internas à Comunicação e outras áreas do conhecimento. A "metapesquisa" vem sendo tematizada em várias instâncias, sugerindo uma postura reflexiva da Área no sentido de pensar sua produção. Para mencionar apenas alguns trabalhos recentes, Mattos, Barros e Oliveira (2018), Wottrich et alli (2020), ou Salgado, Mattos e Oliveira (2020) examinam as produções de dois dos principais eventos da Área, a Compós e a Intercom, mostrando uma produção ramificada em uma considerável diversidade epistemológica.

Finalmente, uma terceira questão, tema deste artigo, diz respeito às publicações: o que as revistas acadêmicas podem dizer sobre suas dinâmicas epistemológicas de produção e circulação do saber? Na prática acadêmica, no cotidiano da "cozinha das ciências" (BOURDIEU, 1983), quem pesquisa encontra materialmente a "teoria" como um conjunto de livros, artigos, textos e leituras a fazer, sem mencionar aulas, seminários, congressos e encontros, conforme o caso. É lá que está a "teoria", o repertório a ser lido, ouvido, discutido e incorporado para a pesquisa presente ou futura.

As revistas, do mesmo modo, são o lugar por excelência de encontrar essa presença contemporânea da teoria. Em certa medida, aprender a ser pesquisador 
significa aprender a garimpar, nesse manancial, quais conceitos efetivamente podem e devem ser usados. Publicações permitem entrever aspectos de elaboração do conhecimento de uma Área, isto é, seus aportes teórico-metodológicos, temáticas e problematizações (FERREIRA, 2003; MARTINO, 2015; 2016).

A história epistemológica de uma área pode ser delineada a partir de um trabalho arqueológico, no sentido de Foucault (2000), com a produção expressa nos artigos de uma revista acadêmica, lugar de encontro da teoria de uma área. No campo científico, argumentam Castedo e Gruszynski (2001, p. 283), as revistas são importantes "na cadeia de difusão e construção do conhecimento científico de cada campo, constituindo-se em espaço de discussão entre agentes altamente especializados em suas áreas do conhecimento". Não se trata, aqui, de recuperar uma história dos periódicos, tarefa realizada, por exemplo, por Stumpf (2006), Romancini (2004), Gonçalves, Ramos e Castro (2006) ou Acquolini (2015), mas pensá-las, a partir de Bourdieu (1976), em termos das condições de geração, acumulação e circulação de um capital simbólico na definição de um espaço relativamente autônomo de saber.

Este artigo delineia alguns dos espaços e condições de circulação da produção científica em Comunicação, tomando como base os periódicos da Área. O objetivo é observar as condições de publicação como variáveis da circulação teórica e, portanto, ligadas a uma epistemologia da Área. A partir do estudo das temáticas, distribuição geográfica/cronológica e as condições de publicação de 52 revistas científicas sediadas em Programas de Pós-Graduação em Comunicação ou associações de pesquisa, foi possível observar três elementos principais, que definem as partes deste texto: (1) como as publicações estão articuladas com a construção de um capital científico específico na Comunicação? (2) O que as temáticas dizem sobre as preocupações epistemológicas da Área? (3) Quais as condições e requisitos para a publicação de textos e como isso aponta para diferenças de acesso aos espaços de publicação?

No que se segue, o texto se desenvolve a partir desses três pontos.

\section{Revistas acadêmicas e campo científico}

Segundo indica Gilbert (1995), as primeiras revistas acadêmicas surgiram a partir da troca de correspondência entre os membros das então recém-criadas sociedades científicas, ganhando, ao longo de três séculos, o formato atual. A publicação se torna um importante fator de prestígio perante os outros colegas, dando 
origem também às primeiras disputas - por exemplo, a disputa entre Leibniz e Newton pela autoria do cálculo infinitesimal. Regras, disputas, prestígio: a gênese do campo acadêmico, entendido no sentido de Bourdieu (1976), passa pelas revistas científicas. Elas se tornaram fundamentais para a definição das fronteiras epistemológicas dos campos do conhecimento que se formavam, garantindo a circulação de ideias e concepções a respeito da realidade. Com isso, pavimentavam uma base para discussões e trocas de ideias em uma área, bem como sua identidade.

Seria difícil, por exemplo, pensar no desenvolvimento das Ciências Sociais sem L'année sociologique, fundada por Émile Durkheim em 1898, ou Actes de la recherche en Sciences Sociales, por Pierre Bourdieu em 1975, assim como Annales d'histoire économique et sociale, de Marc Bloch e Lucien Febvre, define aspectos fundamentais da "Escola dos Anais", na História, e Les Temps Modernes, de Jean-Paul Sartre e Simone de Beauvoir, em 1945.

$\mathrm{Na}$ área de Comunicação, o Journalism and Mass Communication Quarterly, de 1924, e Public Opinion Quarterly, criada em 1937, estão entre as mais antigas e conceituadas publicações internacionais, às quais se pode acrescentar o Journal of Communication, fundado em 1951, todas ainda em circulação. Observar esses momentos iniciais mostram as transformações do que se entendia por "comunicação" nesse momento.

A título de ilustração, o primeiro número do Journalism and Mass Communication Quarterly, de janeiro de 1924, trazia artigos sobre a formação do jornalista, debatendo a necessidade de formação universitária para o exercício da profissão - questão atual quase cem anos depois. Já o primeiro número do Journal of Communication, de maio de 1951, trata de problemas relacionados à fala - algo, hoje, mais próximo da Fonoaudiologia que da Comunicação.

No caso das revistas brasileiras, seu desenvolvimento parece ter sido uma consequência relativamente tardia do estabelecimento dos cursos de comunicação e, posteriormente, de pós-graduação. Talvez não seja coincidência que uma das primeiras publicações tenham sido os Cadernos de Jornalismo e Comunicação do Jornal do Brasil: uma empresa de Comunicação é responsável pela produção e circulação da revista.

Se os primeiros livros acadêmicos sobre comunicação são publicados ainda nos anos 1960, as primeiras revistas aparecem apenas no final da década seguinte: a Revista Intercom acompanha a fundação da associação, em 1977, e Comunicação \& Sociedade, 
em 1979, sediada na Universidade Metodista. Esse descompasso entre uma produção bibliográfica já estabelecida e a criação de periódicos pode ser relacionado também com a preocupação inicial, nos cursos de comunicação, com o ensino de graduação cursos de Jornalismo existiam desde 1947, na Cásper Líbero, e os cursos de Comunicação Social desde 1969.

Apenas a partir dos anos 1970 são estabelecidos os primeiros programas de estudos pós-graduados em Comunicação, na ECA-USP, PUC-SP e na ECO-UFRJ, gerando algumas das condições para a criação de espaços de divulgação de uma produção científica nascente. Tomando como base a data de filiação à Associação dos Programas de Pós-Graduação em Comunicação, a Compós, observa-se que 40 dos 52 PPG que formam a entidade se associaram a ela após o ano 2000. O número de revistas acadêmicas acompanha o aumento dos Programas de Pós-Graduação, que experimentam um vertiginioso crescimento a partir de 2000 (gráfico 01).

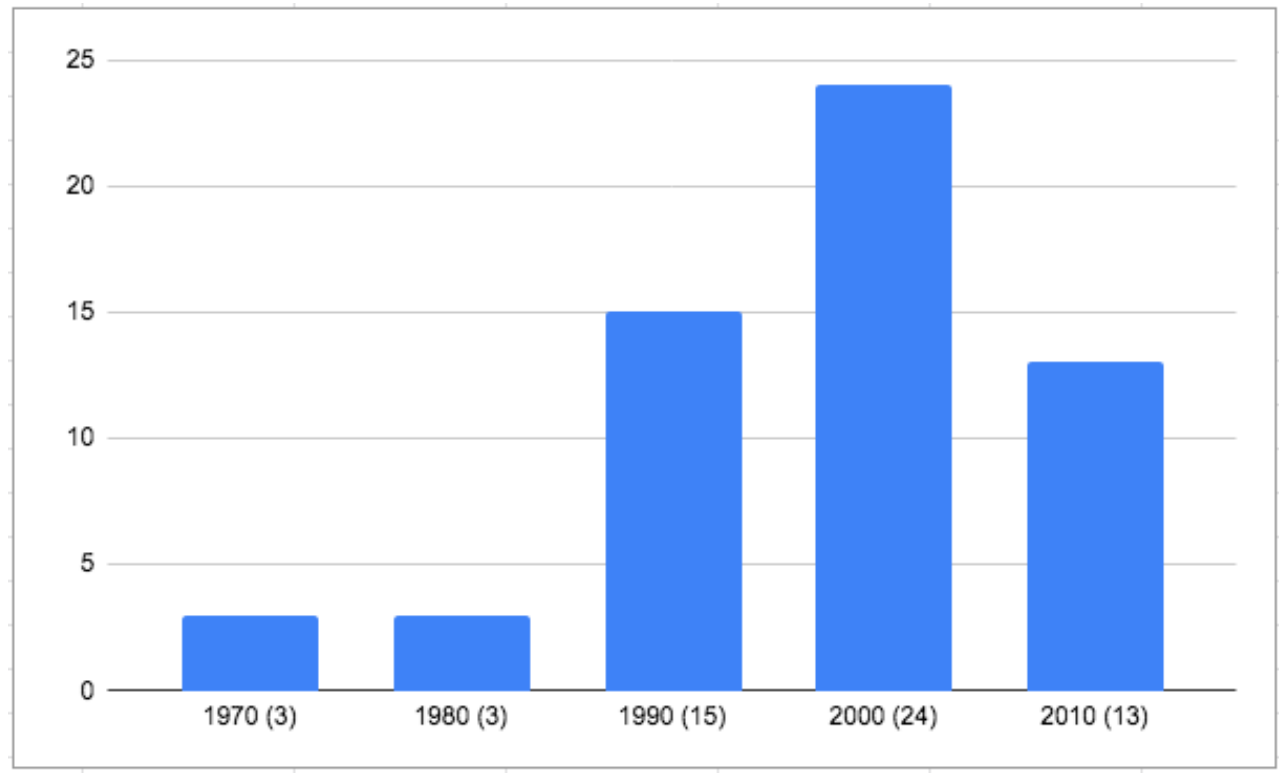

Gráfico 01 - Década de criação das publicações Fonte: Elaborado pelo autor.

A institucionalização da Área parece plenamente consolidada do ponto de vista da existência de uma comunidade acadêmica provida de um circuito de apresentação e troca de ideias. Nas palavras de Lopes (2006, p. 29), "é na década de 1990, com o surgimento de novos programas, que se torna visível o processo de caráter identitário na pós-graduação de Comunicação, no sentido dos programas dotarem-se de maior identidade científica". O crescimento nos anos 2000 pode ser ligado às políticas públicas de expansão e qualificação do ensino superior naquele momento que, embora 
não isenta de contradições, parece ter efetivamente contribuído para uma ampliação dos espaços de produção do saber.

Essa expansão não está livre de desigualdades: se a produção acadêmica não pode ser desvinculada das relações sociais em sua origem, as diferenças na distribuição regional das publicações caminham paralelamente a outras desigualdades verificadas em aspectos semelhantes. Ferreira e Caregnato (2014) mostram, por exemplo, desigualdades de acesso como problemas de visibilidade das revistas e seus conteúdos. Em um estudo sobre as revistas portuguesas, Martins (2012) registra essa desigualdade em termos das barreiras do idioma. O exame da origem geográfica das revistas brasileiras indica algo similar (Quadro 01):

Quadro 01 - Distribuição dos periódicos por região
\begin{tabular}{|l|l|}
\hline Região & Número \\
\hline Sudeste & 23 \\
\hline Sul & 13 \\
\hline Nordeste & 6 \\
\hline Centro-Oeste & 3 \\
\hline Norte & 2 \\
\hline Associações & 4 \\
\hline
\end{tabular}

Quadro 01 - Distribuição dos periódicos por região

Fonte: Elaborado pelo autor.

A predominância de revistas publicadas nas regiões Sul e Sudeste implicam também pensar em sua origem: estão aí não apenas a maior parte dos programas de pósgraduação, mas também alguns dos mais antigos. Nesse aspecto, Bourdieu (2021) assinala que as diferenças de origem na produção de saberes parecem implicar também em uma desigualdade entre os espaços de produção e recepção de conceitos, visível não apenas no número de produções, mas também em seus aspectos de qualificação. Em termos de avaliação qualitativa, os programas mais bem avaliados e a maior parte das revistas com índice Qualis A1 e A2 também estão situadas aí. Esse indicador talvez não seja novidade ou motivo de surpresa, uma vez que se trata de um crescimento visto pela área nas últimas décadas. Cabe questionar, no entanto, em que medida isso não pode ter resultados diretos na circulação de saberes em termos desse tipo de distribuição regional da produção acadêmica.

A questão se relaciona também a uma diversificação dos temas tratados, com algumas tentativas de especialização dentro de assuntos específicos na área de comunicação. Os títulos de algumas revistas sugerem um "campo de interfaces", na expressão de Braga (2004), reconhecível nas conexões entre áreas (“Comunicação e..." 
ou "Mídia e...") ou na adjetivação da palavra "comunicação" para delimitar seu foco. Em alguns casos, a temática está no nome ou subtítulo, como em "Discursos Fotográficos", "Estudos de Jornalismo e Mídia" ou "Questões transversais - revistas de epistemologias da comunicação".

É possível observar, assim, a distribuição dos interesses da área em seis principais temáticas, com ampla variação no número de representantes (Quadro 02):

Quadro 02 - Distribuição dos periódicos por temas
\begin{tabular}{|l|l|}
\hline Foco & Número de revistas \\
\hline Comunicação & 43 \\
\hline Jornalismo & 3 \\
\hline Cinema, Fotografia e Audiovisual & 3 \\
\hline Rádio e Mídia Sonora & 1 \\
\hline Epistemologia & 1 \\
\hline Folkcomunicação & 1 \\
\hline
\end{tabular}

Quadro 02 - Distribuição dos periódicos por temas

Fonte: elaborado pelo autor.

A predominância do tema "comunicação", imediatamente justificável, talvez não possa ser entendido como indício de unidade: é um ponto de relativo consenso entre pesquisadoras e pesquisadores- veja-se, a título de indicação, L. C. Martino (2007), Sodré (2012) ou L. M. Martino (2018) - que o uso da palavra, embora indicador de vínculo institucional, não se traduz unidade conceitual: a noção de "comunicação" em cada uma das revistas pode, efetivamente, variar em relação aos seus limites.

Por outro lado, observa-se também esforços de delimitação temática que parecem corresponder a determinadas clivagens da área, sobretudo em relação ao que se apresenta como uma predominância de questões ligadas aos meios, algo indicado por autores como Luiz C. Martino (2001; 2007), Albuquerque (2002) ou Felinto (2007) no sentido de delimitar alguns aspectos da área a partir das práticas de mídia.

Observa-se, nesse aspecto, a prevalência dos estudos de Jornalismo, com três publicações específicas, e audiovisual também com três, à qual poderia se somar uma dedicada ao rádio e às mídias sonoras. Há, além delas, uma publicação dedicada à epistemologia e outra à folkcomunicação. Essa circunscrição temática não deixa de se apresentar também como delimitação teórica em relação aos conceitos acionados dentro de cada um desses espaços.

Mas o que pode chegar, de fato, a uma publicação? Isso leva ao próximo item.

\section{Os processos de produção da publicação acadêmica}


A manutenção de um conjunto de cinquenta e duas publicações exige da Área um processo amplo de trabalho para tornar possível a circulação dessas ideias. Publicar uma revista científica, em primeiro lugar, de uma decisão institucional de alocar tempo, recursos e pesquisadores para, em meio ao conjunto de atividades acadêmicas, dedicar espaço à criação e manutenção de uma revista.

Como afirmam Thaiane Oliveira et alli (2020, p. 5):

O trabalho de edição de periódicos no Brasil - diferentemente de outros países - é uma atividade que se soma a todas as outras tarefas de pesquisa, ensino e extensão de um pesquisador. Inclui uma enorme abrangência de atividades e de conhecimentos especializados que vão desde a avaliação da qualidade científica e do conhecimento amplo sobre a área ao domínio ferramental das etapas de formatação e revisão, de técnicas de divulgação científica e de estratégias para indexação.

Editadas geralmente por universidades ou associações de pesquisa, elas se apresentam como um retrato da produção intelectual de um campo do saber naquele momento. Sua classificação, aliás, como "periódico", indica essa centralidade do tempo: os textos de uma revista acadêmica têm um compromisso em termos de sua atualidade - não, evidentemente, no sentido de tratar de temas "atuais", mas mostrando as preocupações e assuntos de um campo naquele momento. Bourdieu (1976, p. 91), recorda que

\footnotetext{
isso significa que em um campo científico fortemente autônomo, um determinado produtor só pode esperar o reconhecimento do valor de suas produções ("reputação", "prestígio", "autoridade", "competência", etc.) de outros produtores que, sendo também seus concorrentes, são os menos inclinados a concedê-la sem discussão ou exame.
}

Por isso, além de sua atualidade, revistas acadêmicas são, também, um lugar em que a história do pensamento de um campo fica registrada. No momento de sua publicação, um artigo tem um valor teórico, empírico e interpretativo; anos depois, a esses valores é somado mais um: passa a ser também um documento da história intelectual do campo, registro do que, e como, se pensava em um determinado momento.

Se a estimativa numérica pode ser tomada como ponto de partida, a publicação de cerca de mais de mil artigos científicos mobiliza a elaboração de milhares de pareceres (tomando como índice apenas dois avaliadores por artigo, sem levar em consideração os “empates”, quando uma terceira pessoa é acionada), centenas de 
pessoas em Conselhos Editoriais, além do fundamental apoio técnico para atuar com a publicação em plataformas eletrônicas.

Os editores são trabalhadores essenciais cuja atividade sustenta parte central da avaliação dos programas de pós-graduação no país. No entanto, as políticas de avaliação da pós-graduação brasileiras não consideram esta atuação como uma atividade que pontue positivamente nos mecanismos avaliativos dos programas (OLIVEIRA et alli., 2020, p. 6).

Vale lembrar que, à primeira vista, o processo de edição de uma revista científica possa talvez parecer relativamente simples: criado o espaço, escolhido o nome, define-se uma equipe editorial, geralmente formada por um ou dois editores, geralmente docentes do PPG ou colegas convidados, auxiliares técnicos, funcionários, monitores ou estagiários para colaborar nos encaminhamentos. Berreyre (2013, p.245) lembra que por trás da assinatura de um artigo existe todo um trabalho coletivo que levou à sua publicação.

Um segundo passo é definir um Conselho Editorial, formado por pesquisadoras e pesquisadores renomados, responsáveis pela avaliação dos textos submetidos à revista. As chamadas de trabalhos, publicadas nas listas de e-mails de Universidades e Associações da Área procuram garantir um número de envios suficiente para produzir uma edição dentro dos critérios de qualidade e qualificação.

Os textos são enviados aos pareceristas, e, uma vez avaliados, são publicados ou devolvidos aos autores para correções - em último caso, rejeita-se a publicação. Em geral, cada texto passa por duas leituras, e, em caso de divergências sobre a aprovação, solicita-se uma terceira. Ao final do processo, os artigos com pareceres positivos são publicados, enquanto os demais são devolvidos às autoras e autores para correção, se for o caso, ou com uma recusa e os pareceres negativos. Essa descrição sumária permite observar alguns aspectos do processo e, sobretudo, a quantidade de pessoas, tempo e energia envolvidos.

Mas vale demorar um pouco mais sobre o aspecto da avaliação por pares.

De certa maneira, esse é o momento específico de vinculação a uma "comunidade acadêmica": o momento de ser ouvido - lido, no caso -, comentado e criticado por especialistas. Bomfá e Castro (2004, p. 39) assinalam que “O 'ir e vir' de um artigo para os revisores de uma revista científica é uma das causas apontadas para a lentidão na divulgação das pesquisas nacionais e internacionais (em média dois anos para ser publicado).

Gonçalves, Ramos e Castro (2006, p. 165), afirmam que 
para dar credibilidade ao processo de comunicação da ciência, a revista científica sustenta-se no princípio de validação do mérito e do método científico pela comunidade científica, ou seja, só o que é revisado e aprovado pelos pares deve ser publicado, num processo conhecido como revisão por pares.

Todas as revistas acadêmicas pesquisadas adotam como critério de publicação o sistema de avaliação por pares para decidir quais textos devem ou não figurar na edição. Genericamente, quando um texto chega a uma revista acadêmica, o responsável o encaminha a um ou mais membros do Conselho Editorial, formado por reconhecidas autoridades na área, que o avalia. Em geral, o processo transcorre no completo anonimato, preservando as identidades de autor e avaliador. Esse sistema, internacionalmente utilizado, garante a qualidade e a validade científica: cada texto publicado foi julgado por um colega que atesta seu valor (BERKENKOTTER, 1995).

Trata-se, portanto, de uma situação de tomada de decisão a partir de um critério acadêmico. No entanto, nem sempre esses critérios são colocados em questão. Não se trata de questionar no sentido de duvidar de sua competência ou colocar em dúvida sua validade, mas, na medida em que eles constituem valiosos indícios do que se considera ou não pertinente à publicação, é possível que o estudo dessas avaliações e críticas permita delinear alguns dos parâmetros - em outras palavras, as regras do gatekeeper acadêmico responsável por delinear o que é saber em comunicação (FINN, 1986; MORSE, 2002).

O momento de avaliação de textos para publicação é um dos instantes em que é possível observar a manifestação de pressupostos teórico-epistemológicos como critérios na escolha dos artigos. Para Crigger (1998:457), avaliadores indicam os rumos do conhecimento da área, bem como estabelecer os parâmetros e direções desse conhecimento. Por isso, como indica Bourdieu (2021), não se deve tomar a ideia de uma "comunidade acadêmica" de maneira superficial ou ingênua, descontando os aspectos das linhas de força e disputa que a caracterizam como campo acadêmico. $\mathrm{Na}$ comparação de Silveira (2020, p.3), os avaliadores também agem como "gatekeepers" da produção da Área.

O que pode ser entendido como um "artigo sobre comunicação"? A pergunta torna-se relevante quando se está diante de um artigo remetido para uma revista de comunicação. A questão talvez se torne um pouco mais fácil se reformulada pela antítese: “o que não é um texto sobre comunicação?”. Se, a distância, é possível responder com algum grau de certeza - dificilmente alguém encaminharia um texto 
sobre química orgânica para a revista - o problema ganha volume conforme nos aproximamos das fronteiras da área de comunicação (CRIGGER, 1998).

A publicação ou não de um artigo em uma revista de comunicação aparentemente está ligada, entre outros fatores, ao conceito de "comunicação" em jogo. Vale retomar aqui uma definição de Bourdieu (2021, p. 84) ao afirmar que "a estrutura do campo científico é sempre definida pelo estado da relação de forças entre os protagonistas das disputas, ou seja, pela estrutura da distribuição do capital específico". E essa é a primeira ambiguidade: a noção de "comunicação", seja como campo de estudos, seja como conceito, vem sendo objeto de uma vasta discussão, e embora seja possível encontrar pontos comuns entre as várias definições, seria complexo definir com segurança o que é ou não é "comunicação" (WILLIAMS, 1973; LIMA, 1983; DUARTE, 2003). O problema se estende, igualmente, quando se pensa no que pertence ou não à "comunicação" como área de estudos e/ou campo acadêmico (SANTAELLA, 2001; FELINTO, 2007).

$\mathrm{Na}$ explicação de Barbosa (1983), a situação é ainda mais complexa na fronteira entre Comunicação e Arte: um artigo sobre música ou teatro pode ser considerado “comunicação"? Se adotada uma perspectiva centrada nos meios eletrônicos como área de estudos da Comunicação, certamente não, posto que nem música nem teatro estão ligados, necessariamente, a essa perspectiva (MELO, 1999; ALBUQUERQUE, 2002). No entanto, compreende-se por "comunicação" algo mais amplo, no âmbito interacional, então talvez seja possível aprovar um artigo desse teor (MCQUAIL, 1973; BELTRÃO, 1979; GOMES, 1997). Nas diversas instâncias do trabalho de pesquisa, representadas concretamente por situações que variam da iniciação científica ao doutorado e além, essa prática é progressivamente incorporada, moldando o olhar do pesquisador (GRINGS, 2001; LACERDA, 2003:113).

\section{O "Efeito Mateus", o estilo e as condições de publicação}

A publicação em revistas científicas é um dos pontos centrais da vida acadêmica. Trata-se de um dos critérios apresentados como "objetivos" - embora essa objetividade seja questionável - de avaliação de uma pesquisadora ou um pesquisador. Seria possível argumentar que a capacidade didático-pedagógica em sala de aula também está sujeita à avaliação, com diferentes pesos e resultados institucionais de 
acordo com a situação. No entanto, seus critérios dependem de fatores humanos e pessoais que desaparecem diante dos índices de produção científica.

A nenhuma atividade docente é atribuído um sistema de pontuação como no caso das publicações, baseado em um índice de classificação dos periódicos - o "Qualis". Publicar em revistas situadas nos estratos mais altos (A1 até A4) representa um ganho simbólico de capital científico dentro de um campo e uma pontuação objetiva concedida ao pesquisador. Esses pontos constituem não apenas os índices individuais de produção, mas concorrem também na avaliação dos Programas de Pós-Graduação. Além disso, internacionalmente, a medida do chamado "fator de impacto", isto é, a quantidade de citações recebidas pelos artigos publicados, também uma forma de avaliação da importância de uma revista.

A prática da publicação acadêmica parece se inserir dentro de uma lógica de circulação do capital científico dentro do campo que se desdobra em múltiplas direções: se para pesquisadoras e pesquisadores é importante publicar em revistas situadas nos estratos mais altos, os periódicos também são avaliados e classificados a partir de critérios específicos. Para França e Prado (2013, p. 80), o problema está não só no “grande número de periódicos publicados pela área”, mas também que "esses periódicos ainda não se consolidaram suficientemente e não se criou ainda um elenco nítido de revistas de referência". O resultado são "leituras dispersas e a inexistência de repertórios comuns".

Publicar em uma revista de Qualis A ou com alto fator de impacto significa maior probabilidade de ser lido e citado pelos pares, com uma paralela multiplicação do capital simbólico. Isso gera um efeito peculiar: revistas de maior prestígio publicam artigos que serão mais citados, aumentando, por retroação, a importância do periódico. Algo semelhante tende a acontecer com os artigos: a publicação em uma revista com alto fator de impacto tende a fazer com que o texto seja mais citado, contribuindo para um aumento em espiral.

Em um artigo sobre a circulação do conhecimento científico, dentro de uma perspectiva da Sociologia da Ciência, Merton (2013) denominou esse fenômeno de "Efeito Mateus", ou princípio de vantagem cumulativa. O nome é em referência a um versículo do Evangelho de S. Mateus (25;29): “pois a quem tem, mais será dado, e terá em grande quantidade. Mas, a quem não tem, até o que tem lhe será tirado”. Merton (2013, p. 200) explica que a noção de vantagem cumulativa "dirige nossa atenção para as maneiras pelas quais as vantagens comparativas iniciais, relativas à capacidade 
adquirida, localização estrutural e recursos disponíveis contribuem para incrementos sucessivos de vantagem (...)".

O "Efeito Mateus" define que as desigualdades iniciais (sejam materiais ou simbólicas) nas práticas científicas tendem a se aprofundar, alargando o hiato entre os que partem de uma posição vantajosa em relação aos outros. Para Merton (2013, pp. 199-200),

refere-se aos processos sociais por meio dos quais vários tipos de oportunidades de pesquisa científica, assim como as recompensas simbólicas e materiais subsequentes aos resultados daquela pesquisa tendem a acumular-se para os praticantes individuais da ciência, assim como também para as organizações implicadas no trabalho científico.

Dessa maneira, a tendência de uma revista de prestígio é multiplicar seu capital simbólico, bem como o dos artigos publicados, em detrimento de outras. Esse procedimento tem outro desdobramento: diante da necessidade de publicar em revistas de alto impacto para pontuar mais, pesquisadoras e pesquisadores tendem a direcionar sua produção para as publicações situadas nos estratos mais altos, sobrecarregando os sistemas de avaliação e a capacidade de distribuição dessa demanda entre os pareceristas. Ao mesmo tempo, seria possível pensar uma tendência em deixar de lado publicações com índices menores - o que, por sua vez, tende a dificultar sua ascensão a níveis mais altos, exigindo maiores esforços no sentido de qualificação.

Uma das maneiras é designar uma titulação mínima para a publicação no sentido de indicar a perspectiva de um critério de qualidade para a publicação. Na medida em que um dos itens de qualificação das revistas é a titulação dos autores de artigos, o uso desse critério nas publicações não é uma surpresa. Ao mesmo tempo, cria-se uma considerável barreira para pesquisadoras e pesquisadores nos estágios iniciais numericamente, a maioria em uma área - para encontrar espaços de publicação autoral.

Apenas uma publicação, das 52 analisadas, aceita artigos individuais de graduandos ou mestrandos. A maior parte, dezoito publicações, aceita artigos de mestrandos desde que em coautoria com doutores, prática seguida por outras $4 \mathrm{em}$ relação a mestres e 5 a respeito de doutorandos - que podem publicar individualmente em quatro periódicos, como pode ser observado no quadro 03:

Quadro 03 - Titulação mínima para publicação
\begin{tabular}{|l|l|}
\hline Titulação mínima & Número \\
\hline Doutor & 3 \\
\hline Doutorando & 4 \\
\hline Doutorando (c/ doutor) & 5 \\
\hline Mestre & 4 \\
\hline
\end{tabular}




\begin{tabular}{|l|l|}
\hline Mestre (c/ doutor) & 4 \\
\hline Mestrando & 0 \\
\hline Mestrando (c/ doutor) & 18 \\
\hline Graduando & 1 \\
\hline Graduando (c/ doutor) & 7 \\
\hline Não indica & 7 \\
\hline
\end{tabular}

Quadro 03 - Titulação mínima para publicação

Fonte: Elaborado pelo autor.

Isso permite formular alguns questionamentos a respeito do que se espera da produção de uma Área. Há, ao que parece, uma perspectiva de associação entre titulação e qualidade acadêmica: a prevalência da possibilidade de publicação para doutores em relação aos graus iniciais toma a titulação como premissa e critério precedentes à verificação da qualidade efetiva de um texto.

Soma-se a isso a perspectiva de que o envio de um trabalho para uma revista está ligado à vinculação com pesquisador doutor - na maior parte das revistas, a oportunidade de publicação concentra-se na abertura de possibilidade de coautoria, o que pode implicar na perspectiva dialógica de uma prática de pesquisa conjunta, mas pode igualmente acarretar dificuldades do ponto de vista interpessoal se pautado em uma relação de orientação, como indicam, por exemplo, Umberto Eco (1995), Schnetzler e Oliveira, (2003) e Martino e Marques (2018). A criação de uma "cultura de publicação", como definem Burztyn, Drummond e Nascimento (2010), parece passar por essa perspectiva, ao menos nas etapas iniciais, de um cultivo conjunto.

Essa prática de qualificação a partir da indicação de titulação mínima desdobrase para outro ponto que poderia ser considerado, de certa maneira, um desdobramento do "Efeito S. Mateus": as indicações referentes à possibilidade de publicação de graduandos, graduados, mestrandos e mestres são acompanhadas também, não sem algo de paradoxal, pela perspectiva efetiva de existência de uma produção científica já nessas etapas. Bourdieu (2021, p. 74) lembra que o "requisito de admissão" em um campo é a competência, ou, como denomina, o "capital científico incorporado", mas também a "apetência, a libido scientifica", presumida que leva uma pessoa ainda em espaços iniciais a participar do jogo em cada aspecto da escala - publicar sozinho em uma revista de Qualis menor, publicar com a orientadora ou o orientador em publicação mais bem avaliada, apresentar o trabalho em eventos e assim por diante.

Embora existam duas publicações específicas para a produção discente, nas revistas Anagrama (ECA-USP) e Iniacom (Intercom), parece existir um hiato entre as demandas de produção e as possibilidades efetivas de publicação. A pesquisadora ou 
pesquisador iniciante, nesse cenário, tenderia a apresentar um crescimento mais lento em sua produção em termos objetivos.

Como recorda Maria I. V. Lopes (2006, p. 28):

\begin{abstract}
Por um lado, à medida que crescem os recursos científicos acumulados, que se expressam nos avanços da pesquisa, aumenta o grau de homogeneidade entre os concorrentes e isso faz aumentar a competição científica. Por outro lado, o crescimento da competição científica torna mais acirrada a luta pelos recursos econômicos do campo, que já são, por definição, escassos.
\end{abstract}

A incorporação das regras de campo é presumida naquele que se dispõe a elaborar um texto desse tipo. O domínio da especificidade do texto de relato científico é uma condição para qualquer pesquisador, e a prática de pesquisa tende a reforçar esse modelo de escrita, distinto dos outros. Dito de outra maneira, é possível observar como o cânone dos estudos da comunicação se converte em critérios de avaliação própria da produção da área, auxiliando a definir o próximo texto que será adicionado a esse corpus teórico e, portanto, vai compor esse cânone.

\title{
Considerações finais
}

A produção de mais de mil artigos por ano na área de Comunicação foi um dos pontos de partida para se pensar as questões levantadas neste texto. Trata-se de um indício, evidentemente, aberto a diversas interpretações, das quais foram pensadas, aqui, aquelas relacionadas à distribuição geográfica e cronológica, às condições de produção e à possibilidade de publicação, dentro de uma perspectiva epistemológica.

A ideia de uma história epistemológica de uma área remete às transformações nos saberes que a constitui, tanto em termos de continuidades quanto de rupturas, como lembra Bachelard (2006). A gênese e a transformação dos conhecimentos, para serem compreendidas, parecem requerer, também, o confronto com as condições institucionais de formação desse conhecimento, bem como de sua circulação. Por isso, as revistas acadêmicas se apresentam como um espaço por excelência para compreender essas tranformações.

O estudo das datas de criação, áreas temáticas e condições de publicação das 52 revistas acadêmicas em circulação na Área de Comunicação mostram um panorama multifacetado no que diz respeito tanto à gênese e consolidação do campo quanto a algumas de suas dinâmicas - por exemplo, as diferenças de distribuição regional ou de acesso, bem como a diversidade dos temas presentes. 
Além disso, o número de periódicos, quase na proporção de uma revista para cada PPG, sugere, de um lado, a vitalidade da produção da Área - mas permite também o questionamento a respeito das diferenças entre uma produção relacionada ao compartilhamento de ideias para discussão em uma comunidade acadêmica e a necessidade quantitativa de "produzir". O alto índice de produção sugere uma atenção ao que, de fato, está sendo compartilhado e quais seriam as possibilidades de ampliar a circulação do saber na Área - algo importante para um maior diálogo nas pesquisas sobre Comunicação.

\section{Referências}

ACQUOLINI, Nicole T. Um breve panorama da evolução tecnológica das revistas científicas. ScientiaTec v.2, n.3, p 62-70, jul/dez. 2015.

BACHELARD, Gaston. A formação do espírito científico. Rio de Janeiro: Contraponto, 2006.

BARBOSA, A. M. Questões interdisciplinares em Comunicação. In: MELO, J. M. Ideologia e Poder no Ensino de Comunicação. São Paulo: Cortez, 1983.

BARREYRE, Nicolas. Le travail des revues. In: HUNSMANN, Moritz; KAPP, Sébastien. Devenir chercheur. Paris: EHESS, 2013, p. 245-250.

BERKENKOTTER, C. The Power and the Perils of Peer Review. Rhetoric Review, v. 13, n. 2, Primavera, p. 245-248, 1995.

BOMFÁ, Claudia R. Z.; CASTRO, João E. Desenvolvimento de revistas científicas em mídia digital. Ciências da Informação, v. 33, n. 2, p. 39-48, maio-ago. 2004.

BOURDIEU Pierre. Le champ scientifique. Actes de la recherche en sciences sociales. v. 2, n. 2-3, p. 88-104, junho 1976.

BOURDIEU, Pierre. Questões de Sociologia. Rio de Janeiro: Marco Zero, 1983.

BOURDIEU, Pierre. Para uma sociologia da ciência. Lisboa: Ed. 70, 2021.

CASTEDO, Raquel; GRUSZYNSKI, Ana. A produção editorial de revistas científicas online. Em Questão, Porto Alegre, v. 17, n. 1, p. 271-287, jan./jun. 2011.

CRIGGER, N. What We Owe The Author: rethinking editorial peer review. Nurs Ethics. v. 5 n. $451,1998$.

DUARTE, Elizabeth. Por uma epistemologia da comunicação. In: LOPES, M. I. V. Epistemologia da Comunicação. São Paulo, Loyola, 2003.

FELINTO, Erik. Patologias no sistema da comunicação. In: FERREIRA, G.; MARTINO, L. C. Teorias da Comunicação. Salvador, Ed. UFBA, 2007.

FERREIRA, Ana G.; CAREGNATO, Sonia E. Visibilidade de revistas científicas. TransInformação, Vol. 26, no. 2, maio-ago, pp. 177-190, 2014.

FINN, C. Strengths (And Weaknesses) of Peer Review. Educational Researcher, Vol. 15, No. 7, Ago.- Set., pp. 14-16, 1986

FRANÇA, Vera R. V.; PRADO, José L. A. Comunicação como campo de cruzamentos, entre as estatísticas e o universal vazio. Questões transversais, v. 1, n. 2, p. 76-82, jul./dez. 2013. 
GILBERT, Nigel. Researching social life. Londres: Sage, 1995.

GONÇALVES, Andréa; RAMOS, Lúcia M. S. V. C.; CASTRO, Regina C. F. Revistas Científicas. In: Comunicação \& Produção Científica[ S.l: s.n.], 2006.

GRINGS, C. A pesquisa da pesquisa e a descoberta do transdisciplinar e do transmetodológico. In. MALDONADO, A. E. Perspectivas metodológicas em Comunicação. João Pessoa, Ed. UFPB, 2008.

LOPES, Maria I. V. O campo da comunicação: sua constituição, desafio e dilemas. Famecos, v. 1, n. 30, p. 16-30, ago. 2006.

MARTINS, Moisés L. Revistas científicas de ciências da comunicação em Portugal. Intercom, Vol. 35, no. 1, pp. 233-251, jan-jun 2012.

MARTINO, Luis M. S. . Descontinuidades epistemológicas na Teoria da Comunicação: um estudo das taxonomias entre 1969 e 2011. Logos, v. 22, p. 105-120, 2015.

MARTINO, Luís M. S. . Da Teoria à Metodologia: um ensaio sobre a elaboração de Projetos de Pesquisa em Comunicação. Revista Comunicação Midiática, v. 11, p. 1-15, 2016.

MARTINO, Luís M. S. . Genealogia dos Conceitos na Teoria da Comunicação: esboço de um panorama. Revista Latino-Americana de Ciências de la Comunicación, v. 15, p. 24-35, 2018.

MARTINO, Luís M. S. ; MARQUES, Angela C. S. . A afetividade do conhecimento na epistemologia. Revista Matrizes, v. 12, p. 217-234, 2018.

MATTOS, Maria Angela; BARROS, Ellen J.; OLIVEIRA, Max E. (Orgs.) Metapesquisa em comunicação. Porto Alegre: Sulina, 2018.

McQUAIL, Denis. Introduction and Overview. In: McQUAIL, D. Communication Theory and Research. Londres, Sage, 2001.

MELO, J. M. Apresentação. In: MELO, J. M. (org) Pesquisa em Comunicação no Brasil: Tendências e Perspectivas. São Paulo, Intercom/Cortez, 1983.

MERTON, Robert K. Ensaios de sociologia da ciência. São Paulo: Ed. 34, 2013.

MORSE, J. Considering the 'peer' in peer review. Qualitative Health Research. Vol. 579, No. 12, 2002.

OLIVEIRA, Thaiane et alli. Editorial: E se os editores de revistas científicas parassem? A precarização do trabalho acadêmico além da pandemia. Contracampo, Vol. 9, no. 2, pp. 2-14, 2020.

ROMANCINI, Richard. Periódicos brasileiros em Comunicação: histórico e análise preliminar. XXVII CONGRESSO BRASILEIRO DE CIÊNCIAS DA COMUNICAÇÃO, 27, 2004. Porto Alegre: Anais[...] UFRGS, Setembro de 2004, pp. 1-15.

SALGADO, Tiago; MATTOS, Maria Ângela; OLIVEIRA, Marina. O pensamento comunicacional na Intercom: anais do GP Teorias da Comunicação de 2018 e 2019. CONGRESSO BRASILEIRO DE CIÊNCIAS DA COMUNICAÇÃO, 43, 2020. Anais[...] Salvador: Universidade Federal da Bahia, 01 a 10 de dezembro de 2020, pp. 1-15.

SANTAELlA, Lucia. Comunicação e Pesquisa. São Paulo, Hacker, 2001.

SILVEIRA, Fabrício. Cartografias possíveis: aspectos epistemológicos da circulação do conhecimento no campo da Comunicação. CONGRESSO BRASILEIRO DE CIÊNCIAS DA COMUNICAÇÃO, 43, 2020. Anais[...] Salvador: Universidade Federal da Bahia, 01 a 10 de dezembro de 2020, pp. 1-5.

STUMPF, Ida R. C. Passado e futuro das revistas científicas. Ciência da Informação, Vol. 25, no. 3, 1996, pp. 1-6. 
WOTTRICH, Laura; MAZER, Dulce; MONTEIRO, Maria Clara; CRAVEIRO, Pamela; VIEGAS, Paula. A metodologia na prática de pesquisa em Comunicação: análise de teses e dissertações da região sul. CONGRESSO BRASILEIRO DE CIÊNCIAS DA COMUNICAÇÃO, 43, 2020. Anais[...] Salvador: Universidade Federal da Bahia, 01 a 10 de dezembro de 2020. p. 1-15

\footnotetext{
${ }^{i}$ Professor do Programa de Pós-Graduação em Comunicação da Faculdade Cásper Líbero. Doutor em Ciências Sociais pela PUC-SP. Autor dos livros "Teoria da Comunicação", "Métodos de Pesquisa em Comunicação" e "Comunicação e Identidade", entre outros.
} 